\title{
Design and Testing of CPAS Main Deployment Bag Energy Modulator
}

\author{
Catherine Mollmann* \\ Airborne Systems North America, Pennsauken Township, NJ, 08109
}

\begin{abstract}
During the developmental testing program for CPAS (Capsule Parachute Assembly System), the parachute system for the NASA Orion Crew Module, simulation revealed that high loads may be experienced by the pilot risers during the most devere deployment conditions. As the role of the pilot parachutes is to deploy the main parachutes, these high loads introduced the possibility of main deployment failure. In order to mitigate these high loads, a set of energy modulators was incorporated between the pilot riser and the main deployment bag. An extensive developmental program was implemented to ensure the adequacy of these energy modulators. After initial design comparisons, the energy modulator design was validated through slow-speed joint tests as well as through high-speed bungee tests. This paper documents the design, development, and results of multiple tests completed on the final design.
\end{abstract}

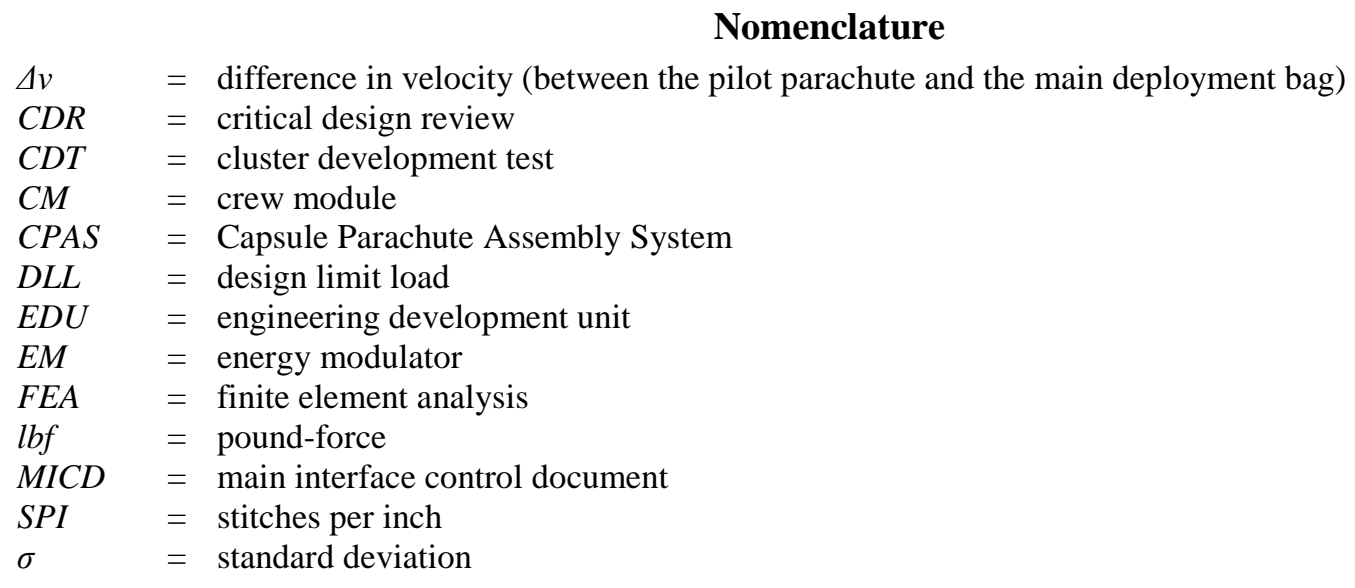

\section{Introduction}

$\mathrm{D}$ URING the development of CPAS, the parachute system for the NASA Orion Crew Module, simulation indicated that the pilot parachutes may experience significantly high loads. As each of the three pilot parachutes is responsible for deploying a main parachute, these loads incited some concerns for pilot performance under the most severe deployment conditions. In order to mitigate these concerns, an analysis model was used to predict the maximum possible force seen by the pilot parachute when deploying the main parachute. Analysis predicted the potential for a significant snatch force when the main deployment bag (containing the main parachute) was lifted from the forward bay by the pilot parachute under maximum $\Delta \mathrm{v}$ (difference in velocity) conditions. This $\Delta \mathrm{v}$ is exacerbated by the time it takes for the pilot to reach line stretch (with a long riser), inflate, and release the entire retention system. Analysis predicted a maximum force of $\sim 18,300 \mathrm{lbf}$, which is significantly higher than the pilot DLL (design limit load, $\sim 7,600$ lbf). This analysis, even though it contained multiple conservative assumptions, reinforced the concerns about exceeding the pilot DLL.

In order to keep the maximum pilot load below the DLL, an energy modulator was designed and implemented. Energy modulators are used on many systems to absorb energy (which typically lowers the peak load); they normally consist of webbing folded and sewn to itself that then peels under load. The energy modulator for this situation was

*Production Engineer, Engineering, 5800 Magnolia Ave, Pennsauken, NJ, 08109, AIAA Member. 
incorporated between the bag handles of the main deployment bag and the pilot retention release bridle (an extension of the pilot riser). See Figure 1. At this location, any significant loads could be mitigated immediately before lifting the main deployment bag. Additionally, the MICD (main interface control document) at this location, which is the allowable volume allocation, had sufficient space in which to store the energy modulator.

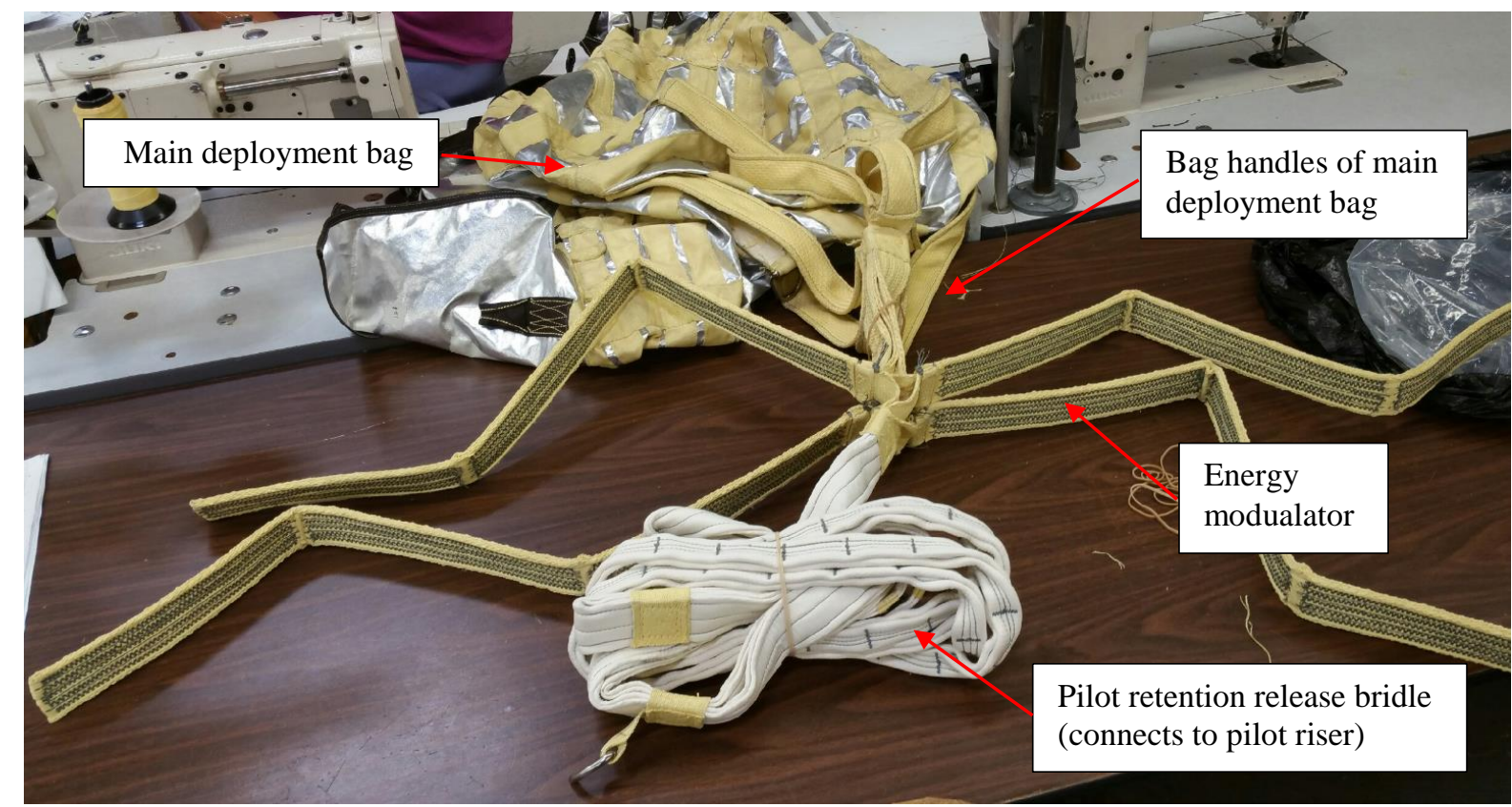

Figure 1: Incorporation of Energy Modulator

Several steps were taken to design and test the energy modulator. An initial design study was completed using low-speed strip out tests on three competing designs. At this point, because of limited schedule, the best design was implemented on the remaining EDU (engineering development unit) tests. Concurrent to the manufacturing of these assets, formal seam and joint tests were completed (at slow-speed). While all CPAS seam and joint tests are completed at slow-speed (typically $12 \mathrm{in} / \mathrm{min}=0.0167 \mathrm{ft} / \mathrm{s}$ ), the actual speed at strip out during deployment is significantly higher $(\sim 150 \mathrm{ft} / \mathrm{s})$. In order to validate the slow-speed data, further strip-out tests were completed using a bungee system at higher speeds. Finally, informal slow-speed testing was completed to determine if repair and re-use of the energy modulator during CPAS qualification testing resulted in any appreciable tear strength degradation.

The energy modulator detailed in this paper was implemented on CDT 3-16 and CDT 3-17 (CDT = cluster development test), the last two EDU tests. Based on its positive performance, it was also incorporated into the final design presented at CDR (critical design review) and is being built for all qualification and flight tests.

\section{Initial Design Study}

During the initial design phase of the energy modulator, the goal was to achieve the highest tear strength with minimal degradation to the base webbing. The base webbing, as well as being part of the energy modulator, also constitutes the bag handles of the main deployment bag and the pilot retention release bridle. Any degradation to the base webbing would have to be accounted for in the margin of safety analysis. Samples with different stitch patterns were constructed to assess the tear strength and degradation and to determine the length of stitch pattern needed for the final design.

In order to prevent the energy modulators from stroking under a small load, each energy modulator is initially inhibited by a "force limiting tie" constructed from Nylon thread. The collective strength of all of the force limiting ties is designed to be less than the pilot parachute design limit load (see Section II.0.2).

\section{A. Initial Design}

\section{Energy Modulator Stitch Pattern}

To assess the effects of different designs, three energy modulator configurations with six test samples each were designed and constructed. All configurations consisted of Nylon thread sewn to 1.75" wide, 15,000 lbf minimum breaking strength Kevlar webbing: 
1. Design 'A': 6 rows of zigzag with Nylon thread, A-A-59826 size '6', 6-7 SPI (stitches per inch) (see Figure 2):

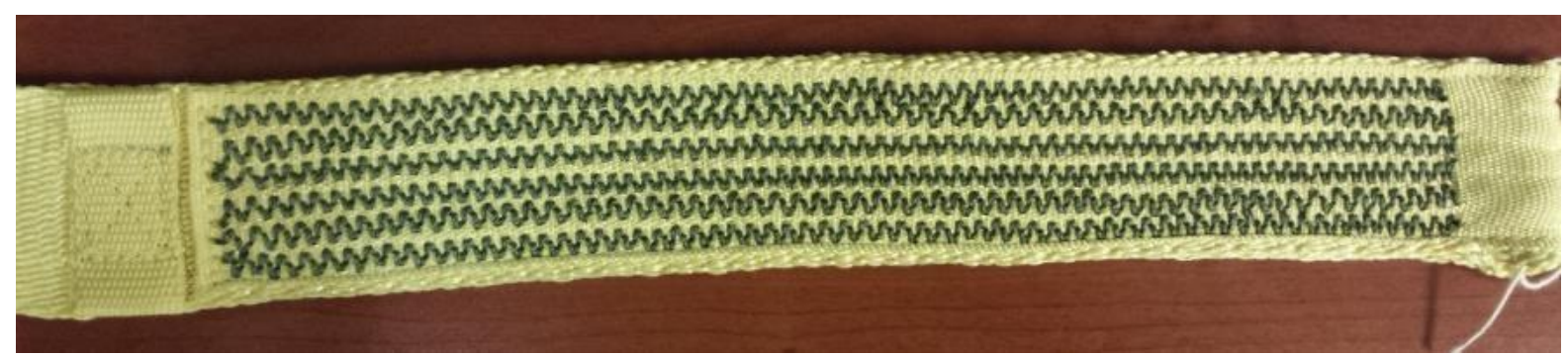

Figure 2: Design 'A' Sample

2. Design 'B': 10 rows of zigzag with Nylon thread, A-A-59826 size '3', 6-7 SPI (see Figure 3):

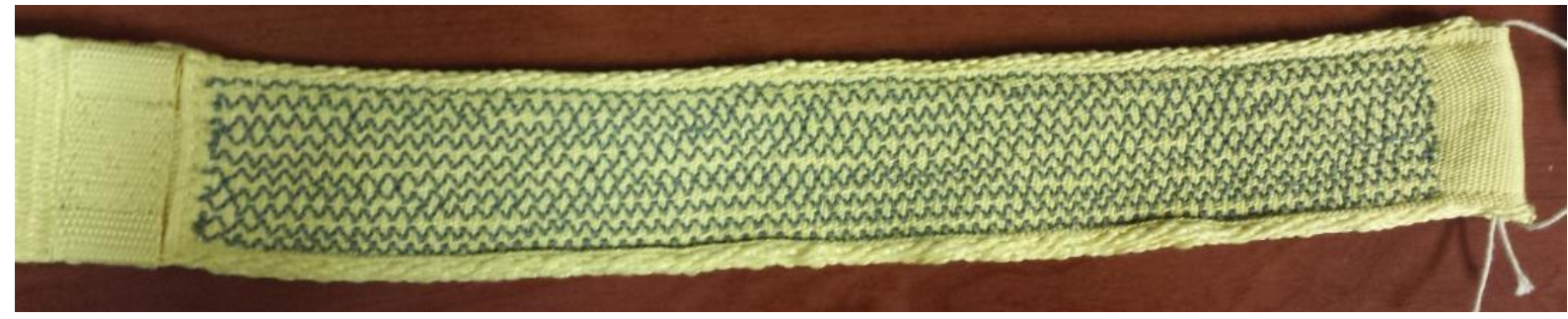

Figure 3: Design 'B' Sample

3. Design ' $\mathrm{C}$ ': 5 rows of zigzag interspersed with 4 rows of straight stitch, all with Nylon thread, A-A-59826 size '6', 6-7 SPI (see Figure 4):

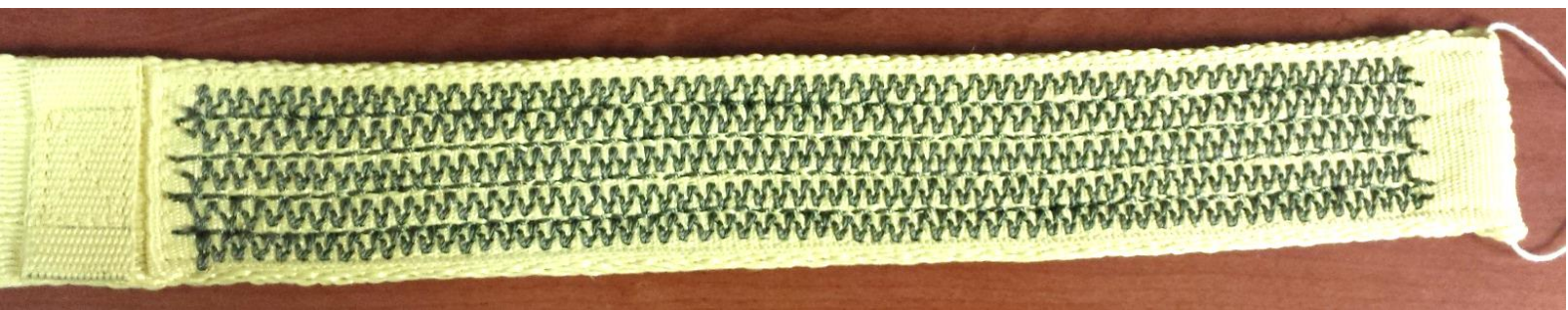

Figure 4: Design 'C' Sample

Typically, the SPI for zigzag stitching with size ' 3 ' or ' 6 ' thread is 4-7. In each of the three designs, the SPI range was restricted to 6-7 SPI. This allowed for less potential variation in the final product and also ensured that the stitch pattern was as strong as possible.

\section{Force Limiting Tie}

Each energy modulator is initially prohibited from stroking by two force limiting ties, one on each side of the webbing (see Figure 5).

For each set of six samples, different configurations of force limiting ties were constructed:

1. Design ' $A$ ': 10 turns of Nylon thread, A-A-59826 size ' 6 '

2. Design 'B': 8 turns of Nylon thread, A-A-59826 size ' 6 '

3. Design ' $\mathrm{C}$ ': 6 turns of Nylon thread, A-A-59826 size ' 6 '

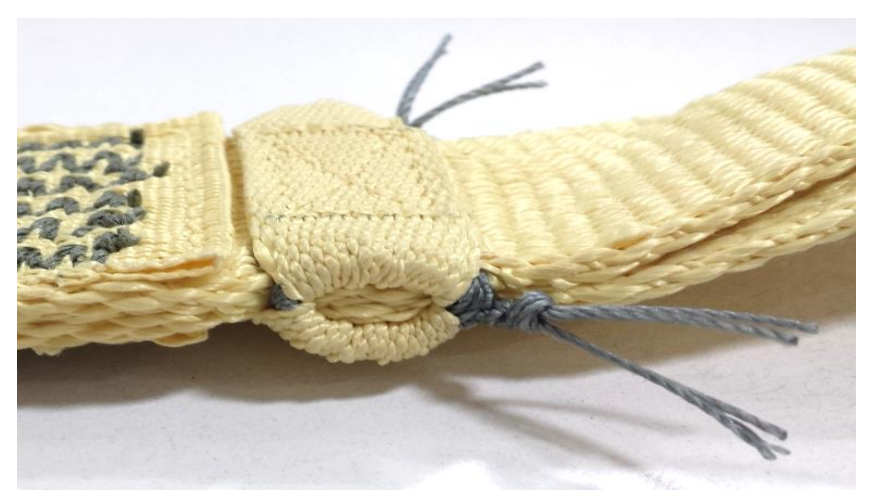

Figure 5: Force Limiting Tie 
An estimate for the strength of each force limiting tie can be calculated using a basic strength equation that takes into account the number of turns and strength of the material (see Section II.0.2). In order to use that equation, a derating factor is needed to account for load sharing and any knot efficiencies; the results from breaking each of the samples allows for the calculation of this de-rating factor (see Section II.C.2).

\section{B. Test Methodology and Procedure}

In addition to the 18 ( 6 each $* 3$ designs) test samples, control samples of the base webbing were constructed. The standard Sedam grips were used to test the strength of the control samples and all of the test samples (see Figure 6).

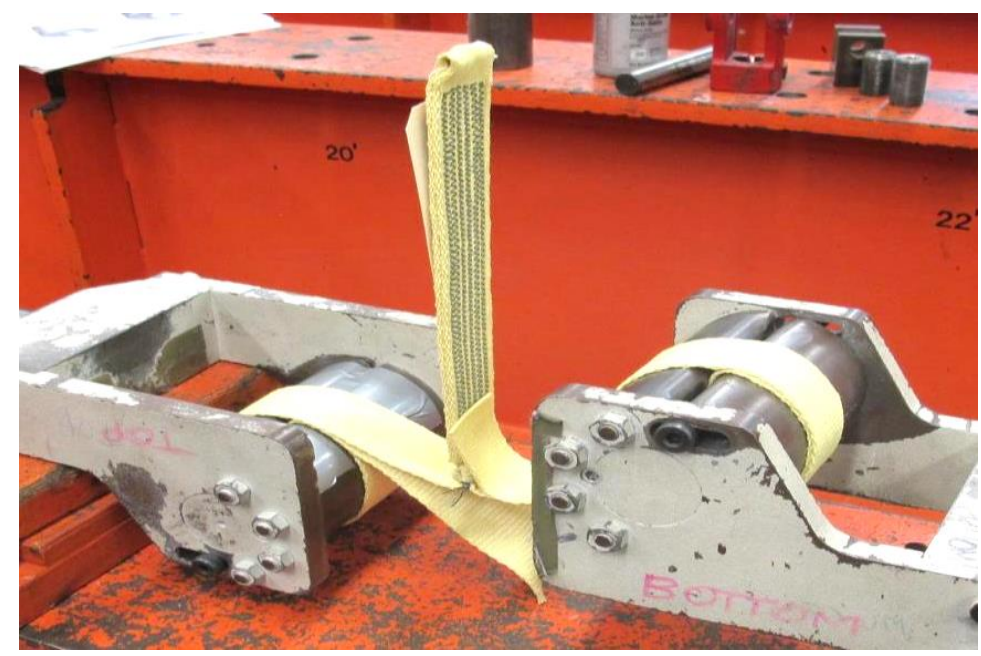

Figure 6: Test Set-Up

Six samples were constructed for each of the three designs. Three of the six samples were pulled to failure, while the other three were stopped after the energy modulator was stroked. The sequence of test events was as follows:

- Broke the force limiting ties

- Stroked the energy modulator

- Pulled the webbing to failure (3 of 6 samples per design)

The remaining (unbroken) three samples from each design were repaired and re-stroked twice more, in order to simulate reuse during qualification testing. See Section V.

\section{Results}

1. Energy Modulator Stitch Pattern Strength

Table 1 below summarizes the results of the stitch patterns for the three configurations:

Table 1. Energy Modulator Stitch Pattern Strength Results

\begin{tabular}{|c|c|c|c|}
\hline Design & 'A' & 'B' & 'C' \\
\hline Average Tear Strength (lbf) & 978 & 759 & 991 \\
\hline Standard Deviation Tear Strength (lbf) & 96 & 60 & 106 \\
\hline Thread Specification Strength (lbf) & 54.0 & 27.0 & 54.0 \\
\hline Thread Actual Strength (lbf) & 69.4 & 33.1 & 69.4 \\
\hline Minimum SPI & 6 & 6 & 6 \\
\hline Maximum SPI & 7 & 7 & 7 \\
\hline Minimum Strength of Stitch Pattern (lbf) & 588 & 489 & 590 \\
\hline
\end{tabular}

Where the minimum strength of the stitch pattern is calculated by:

\section{Minimum Stitch Pattern Strength}

$$
=(\text { Average Tear Strength }- \text { St Dev Tear Strength })\left(\frac{\text { Thread Spec Strength }}{\text { Thread Actual Strength }}\right)\left(\frac{S P I_{\min }}{S P I_{\max }}\right)
$$


The minimum stitch pattern strength represents the lowest possible strength of that stitch pattern, assuming that the thread could be at minimum specification strength and that the operator sews the pattern at the minimum SPI (stitches per inch).

2. Force Limiting Tie

Table 3 summarizes the results of the force limiting tie strength. Data from Design ' $\mathrm{C}$ ' configuration is omitted, as the breaking values were very close to the energy modulator tear strength values, and thus unable to be determined with any accuracy:

Table 2. Force Limiting Tie Results

\begin{tabular}{|c|c|c|}
\hline Design & ${ }^{\mathbf{6}} \mathbf{A}$ & ${ }^{\mathbf{~}} \mathbf{B}$ \\
\hline Average Initial Peak Value (lbf) & 1358 & 1103 \\
\hline Number of Turns & 10 & 8 \\
\hline Number of Plies per Turn & 2 & 2 \\
\hline Actual Thread Strength (lbf) & 75.7 & 75.7 \\
\hline Theoretical Peak Value (lbf) & 1515 & 1212 \\
\hline De-Rating Factor & 0.90 & 0.91 \\
\hline
\end{tabular}

Where the de-rating factor is calculated by:

$$
\begin{gathered}
\text { De-rating Factor }=\frac{\text { Average Initial Peak Force }}{\text { Theoretical Peak Force }} \\
=\frac{\text { Average Initial Peak Force }}{(\text { Number of Turns)(Number of Plies per Turn)(Actual Thread Strength) }}
\end{gathered}
$$

\section{Base Webbing Joint Efficiency}

Joint efficiency is a measure of the degradation to a base material due to interaction with other components or sewing; it is used in conjunction with other degradation factors in the calculation of the margin of safety for each structural parachute component. Table 2 below summarizes the results of the joint efficiency of the base webbing for the three configurations:

\begin{tabular}{|c|c|c|c|}
\hline Design & 'A' & 'B' & 'C' \\
\hline Average Breaking Strength (lbf) & 10,723 & 13,334 & 12,501 \\
\hline Standard Deviation Breaking Strength (lbf) & 634 & 960 & 270 \\
\hline Average Control Strength (lbf) & 17,391 & 17,391 & 17,391 \\
\hline Number of Plies & 1 & 1 & 1 \\
\hline Joint Efficiency & 0.58 & 0.71 & 0.70 \\
\hline
\end{tabular}

Table 3. Base Webbing Joint Efficiency Results

Where the joint efficiency is calculated by:

$$
\text { Joint Efficiency }=\frac{\text { Average Breaking Strength }- \text { St Dev Breaking Strength }}{(\text { Average Control Strength })(\text { Number of Plies })}
$$




\section{Analysis of Results}

\section{Energy Modulator Stitch Pattern}

The final design of the stitch pattern was chosen by comparing the results from the stitch pattern strength results (Section A.C.1) and the joint efficiency results (Section A.C.2). These results are summarized in Table 4:

Table 4. Summary of Stitch Pattern Strengths

\begin{tabular}{|c|c|c|c|}
\hline Design & 'A' & 'B' & 'C' \\
\hline Minimum Strength of Stitch Pattern (lbf) & 588 & 489 & 590 \\
\hline Standard Efficiency & 0.58 & 0.71 & 0.70 \\
\hline
\end{tabular}

For both of the criteria, higher values indicate a superior design. For these reasons, the ' $\mathrm{C}$ ' design was chosen for the final design.

The length of the energy modulator (EM) stitch pattern was calculated based on the minimum strength of the stitch pattern and the energy that is required to be dissipated. The energy from the snatch load was determined using FEA (finite element analysis) under worst-case conditions. Since this calculation uses both a worst-case stitch pattern strength and a worst-case energy requirement, the resulting total stitch pattern length per EM is very conservative (especially for nominal flight conditions). See Table 5.

Table 5. Length of Required Stitch Pattern

\begin{tabular}{|c|c|}
\hline Design & 'C' \\
\hline Energy from Snatch Load (lbf-ft) & 12,810 \\
\hline Number of Energy Modulators in Parallel & 4 \\
\hline Energy Required per EM (lbf-in) & 38,430 \\
\hline Minimum Strength of Stitch Pattern (lbf) & 590 \\
\hline Total Rip Length Needed per EM (in) & 65.14 \\
\hline Stitch Pattern Length per EM (in) & 32.57 \\
\hline
\end{tabular}

Where the stitch pattern length per energy modulator is calculated by:

$$
\begin{aligned}
\text { Energy Required per } E M & =\frac{\text { Energy from Snatch Load }}{\text { Number of Energy Modulators }} \\
\text { Total Rip Length Needed per } E M & =\frac{\text { Energy Required per } E M}{\text { Minimum Strength of Stitch Pattern }} \\
\text { Stitch Pattern Length per } E M & =\frac{\text { Total Rip Length Needed per EM }}{2}
\end{aligned}
$$

A quantity of four energy modulators in parallel was chosen for the final design. This was the default choice, as there are four plies of Kevlar ${ }^{\circledR}$ webbing in the pilot retention release bridle. Using four energy modulators in parallel also allows for the total energy modulator length to be spread over four separate pieces, making it easier to manufacture and to sew.

\section{Force Limiting Tie}

The design limit load of the pilot parachute is $\sim 7600 \mathrm{lbf}$. The energy modulators must stroke before this load is reached; therefore, the strength of all of the force limiting ties must be below this value for all possible conditions. The maximum strength of the force limiting ties is calculated by:

$$
\begin{aligned}
& \text { Maximum Force Limiting Tie Strength } \\
& \qquad \begin{array}{l}
=(\text { Maximum Thread Strength })(\text { Number of Turns })\left(2 \frac{\text { plies }}{\text { turn }}\right)\left(2 \frac{\text { ties }}{E M}\right)(4 \text { EM total })(\text { de } \\
- \text { rating factor })
\end{array}
\end{aligned}
$$

A de-rating factor of 0.90 was used, based on the test data summarized in Section A.C.2.

The Nylon ' 6 ' cord used for the tie is always received at or above the minimum value specified in A-A-59826, 54 lbf. The maximum possible breaking strength of this cord was determined through an assessment of previously 
received lots of the material. The average $+3 \sigma(3 *$ standard deviation) value from these lots was used as the "maximum thread strength" in the above equation. See Table 7:

Table 7. Received Lot Data for Nylon ' 6 ' Cord, A-A-59826

\begin{tabular}{|c|c|}
\hline Lot & $\begin{array}{c}\text { Average Breaking } \\
\text { Strength (lbf) }\end{array}$ \\
\hline $\mathbf{1}$ & 77.6 \\
\hline $\mathbf{2}$ & 80.9 \\
\hline $\mathbf{3}$ & 73.9 \\
\hline $\mathbf{4}$ & 75.9 \\
\hline $\mathbf{5}$ & 78.4 \\
\hline $\mathbf{6}$ & 79.3 \\
\hline $\mathbf{7}$ & 69.9 \\
\hline $\mathbf{8}$ & 76.3 \\
\hline $\mathbf{9}$ & 69.9 \\
\hline Maximum & 80.9 \\
\hline Minimum & 69.9 \\
\hline Average & 75.8 \\
\hline $\begin{array}{c}\text { Standard } \\
\text { Deviation }\end{array}$ & 3.9 \\
\hline $\begin{array}{c}\text { Average }+ \\
\text { 3*Standard } \\
\text { Deviation }\end{array}$ & 87.5 \\
\hline
\end{tabular}

Using the above equation, the number of turns can be determined for each force limiting tie. Table 6 shows the force limiting tie strength using 6 turns and various values for the maximum thread strength:

Table 6. Force Limiting Tie Strength

\begin{tabular}{|c|c|c|c|}
\hline \multicolumn{2}{|c|}{ Strength of Thread Used in Calculation (lbf) } & $\begin{array}{c}\text { Number } \\
\text { of Turns }\end{array}$ & $\begin{array}{c}\text { Total Force Limiting } \\
\text { Tie Strength (lbf) }\end{array}$ \\
\hline Specification (Minimum Possible) & 54.0 & 6 & 4666 \\
\hline Minimum Received & 69.9 & 6 & 6039 \\
\hline Average Received & 75.8 & 6 & 6549 \\
\hline Maximum Received & 80.9 & 6 & 6990 \\
\hline Average + 3*Standard Deviation & 87.5 & 6 & 7560 \\
\hline
\end{tabular}

Table 6 shows that using the average $+3 \sigma$ value results in a total force limiting tie strength less than $7600 \mathrm{lbf}$. More realistic thread strength values, such as the average or the maximum, result in values in the 6500-7000 lbf range.

As stated in Section A.C.2, the strength of 6 turns of ' 6 ' cord on both sides of the energy modulator is usually indistinguishable from the rip strength of the energy modulator itself. Nevertheless, the requirement to not overload the pilot parachute results in this configuration.

\section{E. Overview of Final Configuration}

To summarize, the final design is:

- Number of energy modulators in parallel: 4

- Stitch pattern:

$\circ 5$ rows of zigzag interspersed with 4 rows of straight stitch

- Nylon thread, A-A-59826 size ' 6 '

- 6-7 SPI

○ Sewn length of 32.50" (for each of the 4 legs)

- Force limiting tie:

○ 6 turns of Nylon ' 6 ' cord

- 2 ties per energy modulator 


\section{Formal Joint Efficiency Results}

The initial design trades were completed with 6 samples of each design, where only 3 were pulled completely to failure. The joint efficiency calculated from these 3 samples was used for reference purposes during the initial design only. To determine the joint efficiency of the bridle at this location, formal seam and joint testing was completed with 10 total samples at low speed. Reference "Determination of Parachute Joint Factors using Seam and Joint Testing"" for more information on seam and joint testing.

\section{A. Test Methodology and Procedure}

Samples with the final (design ' $\mathrm{C}$ ') energy modulator stitch pattern design were constructed to a slightly modified configuration, called design 'D' (see Figure 7).

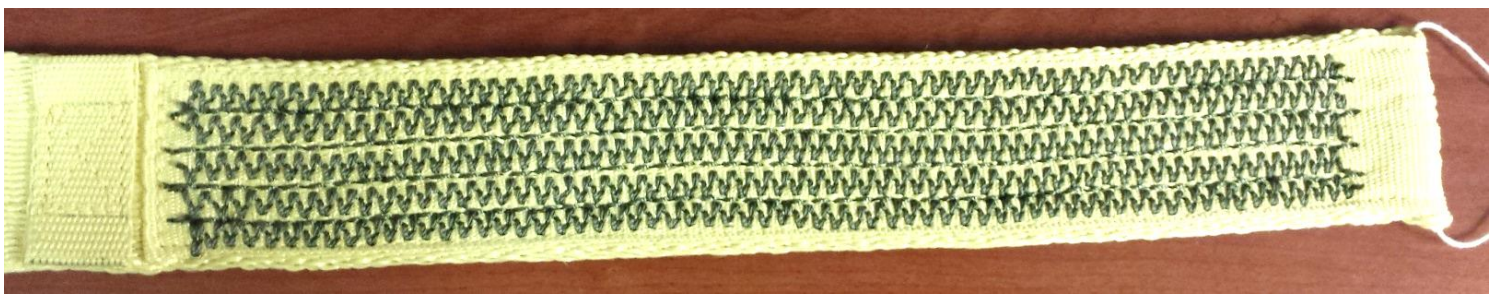

Figure 7: Design 'D' Sample

The beckets on each side of the energy modulator, used for the force limiting ties, tended to rip off during the testing of the initial design samples. Therefore, the strength of the stitch pattern used to secure these beckets was improved by increasing the strength of the Kevlar thread. This resulted in a design change from ' $C$ ' to ' $\mathrm{D}$ ', but the energy modulator stitch pattern itself did not change.

The test samples and control samples were tested on a tensile testing machine with a $30 \mathrm{k}$ capacity. Sedam grips were used on either end of the test fixture in order to interface with the webbing (see Figure 8).

All samples were pulled to failure at a rate of $12 \mathrm{in} / \mathrm{min}$, per standard CPAS seam and joint practices.

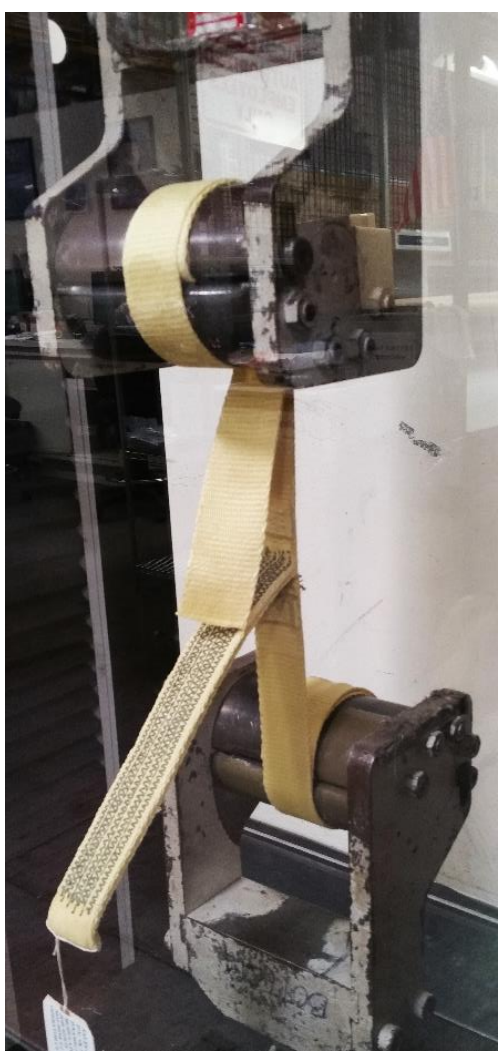

Figure 8: Formal Joint Efficiency Test Set-Up 


\section{B. Results and Analysis of Results}

1. Joint Efficiency

Table 8 below summarizes the results of the joint efficiency of the retention release bridle at the energy modulator. Also calculated is the mean efficiency, a less conservative measure of the degradation:

Table 8. Formal Joint Efficiency Results

\begin{tabular}{|c|c|}
\hline Average Breaking Strength (lbf) & 11,304 \\
\hline Standard Deviation Breaking Strength (lbf) & 602 \\
\hline Average Control Strength (lbf) & 17,588 \\
\hline Number of Plies & 1 \\
\hline Mean Efficiency & 0.64 \\
\hline Standard (Joint) Efficiency & 0.61 \\
\hline
\end{tabular}

Where the efficiencies are calculated by:

$$
\begin{aligned}
\text { Mean Efficiency } & =\frac{\text { Average Breaking Strength }}{(\text { Average Control Strength })(\text { Number of Plies })} \\
\text { Standard (Joint) Efficiency } & =\frac{\text { Average Breaking Strength }- \text { St Dev Breaking Strength }}{(\text { Average Control Strength })(\text { Number of Plies })}
\end{aligned}
$$

2. Energy Modulator Stitch Pattern Strength

Although not a requirement for this test, the strength of the energy modulator stitch pattern for each samples was determined using the force vs. time data. See Table 9. Sample 6 data is omitted, as there was a problem with the test set-up that was not discovered until after the test was begun.

Table 9. Formal Energy Modulator Stitch Pattern Strength Data

\begin{tabular}{|c|c|c|}
\hline Sample & $\begin{array}{c}\text { Average Tear } \\
\text { Strength (lbf) }\end{array}$ & $\begin{array}{c}\text { Standard Deviation } \\
\text { Tear Strength (lbf) }\end{array}$ \\
\hline $\mathbf{1}$ & 954 & 171 \\
\hline $\mathbf{2}$ & 980 & 142 \\
\hline $\mathbf{3}$ & 959 & 126 \\
\hline $\mathbf{4}$ & 1018 & 144 \\
\hline $\mathbf{5}$ & 937 & 171 \\
\hline $\mathbf{6}$ & -- & -- \\
\hline $\mathbf{7}$ & 936 & 127 \\
\hline $\mathbf{8}$ & 967 & 144 \\
\hline $\mathbf{9}$ & 971 & 148 \\
\hline $\mathbf{1 0}$ & 940 & 202 \\
\hline Average & 962 & 153 \\
\hline $\begin{array}{l}\text { Standard } \\
\text { Deviation }\end{array}$ & 26 & 25 \\
\hline
\end{tabular}


The tear strength from these formal samples is very similar to that of the initial design study samples, $991 \mathrm{lbf}$ average and $106 \mathrm{lbf}$ standard deviation (from Section II.C.1). The average of the average tear strength and standard deviation tear strength can be used to calculate the minimum strength of the stitch pattern. See Table 10:

Table 10. Formal Energy Modulator Stitch Pattern Strength Results

\begin{tabular}{|c|c|}
\hline Average Tear Strength (lbf) & 962 \\
\hline Standard Deviation Tear Strength (lbf) & 153 \\
\hline Thread Specification Strength (lbf) & 54.0 \\
\hline Thread Actual Strength (lbf) & 69.4 \\
\hline Minimum SPI & 6 \\
\hline Maximum SPI & 7 \\
\hline Minimum Strength of Stitch Pattern (lbf) & 540 \\
\hline
\end{tabular}

Where the minimum strength of the stitch pattern is calculated by:

Minimum Stitch Pattern Strength

$=($ Average Tear Strength - St Dev Tear Strength $)\left(\frac{\text { Thread Spec Strength }}{\text { Thread Actual Strength }}\right)\left(\frac{S P I_{\min }}{S P I_{\max }}\right)$ 


\section{High-Speed Bungee Tests}

All slow-speed tests were completed under constant speeds at $12 \mathrm{in} / \mathrm{min}$ or less $(\leq 0.0167 \mathrm{ft} / \mathrm{s})$. During actual drop tests and flights, the initial difference in speed between the pilot parachute and the main deployment bag upon bag pick-up is between 100-200 ft/s. As the initial design study and the determination of the length of the energy modulator was based on the slow-speed results, concern existed over the performance of the energy modulator at those higher speeds. Therefore, a high-speed test campaign was developed and executed to validate the design at an initial speed of about $150 \mathrm{ft} / \mathrm{s}$.

\section{A. Overview of Test}

A single bungee with multiple wraps was used to accelerate a given mass to the desired velocity. The momentum of the mass produced enough force to partially strip the stitches in the energy modulator. Figure 9 shows an overview of the complete test set-up and components:

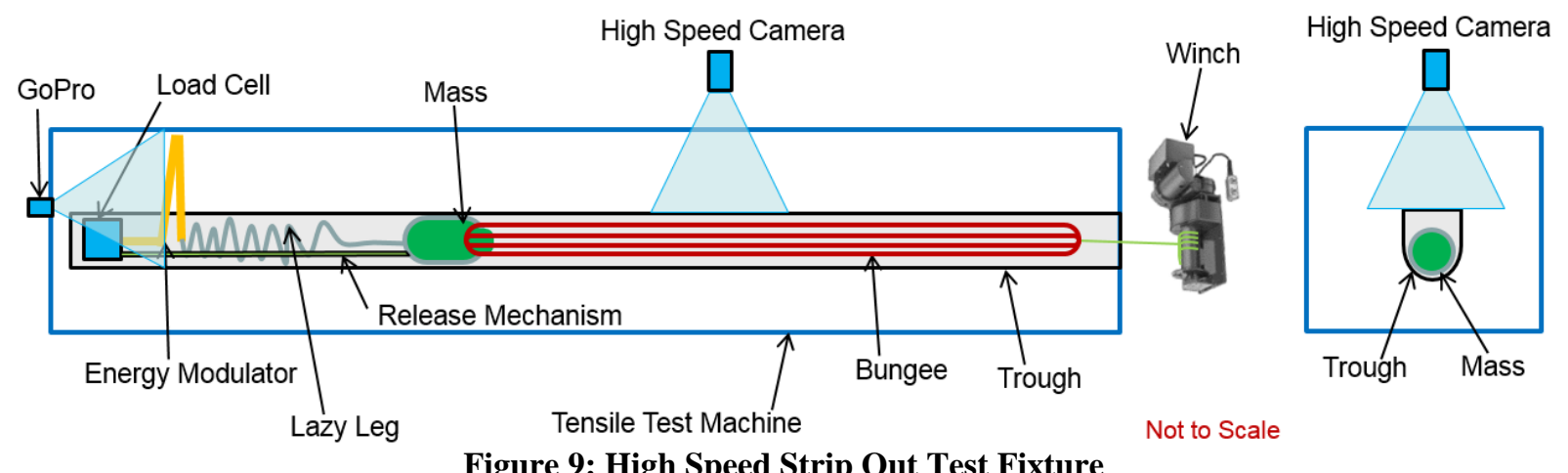

For the tests, the bungee was stretched to a pre-determined length with the mass at one end inside of the test fixture. During the set-up for each test, the force in the bungee was withheld from the energy modulator through the use of a 3-ring release strap. After the bungee was stretched to the desired load/length, the 3-ring strap was released. This allowed the bungee to retract to its original length, moving the mass down the trough. At a pre-determined location, the mass, connected to the energy modulator via a lazy leg, loaded and tore the energy modulator. A load cell was connected to both the energy modulator and the bungee; this allowed for load measurements both prior to mass release (in the bungee) and as the energy modulator was tearing.

Figure 10 depicts one end of the test set-up before bungee loading. The load cell is on the far right of the photo and the trough continues past the edge of the photo to the left. This photo was taken with the lazy leg fully extended.

Figure 11 was taken at the same time as Figure 10 but at a different location-a viewing area about halfway down the trough. A high-speed camera was mounted above this area in order to capture the velocity of the mass at the time that the lazy leg was tensioned (which is when the energy modulator began to tear). To aid in the velocity determination, stripes of a known width were painted.

Figure 12 depicts a complete test set-up. The mass is now connected to the 3-ring release strap. The lazy leg is stored just above the trough in order to not interfere with the mass after release. After this photo was taken, the bungee was stretched to the pre-determined length and the test could begin. 

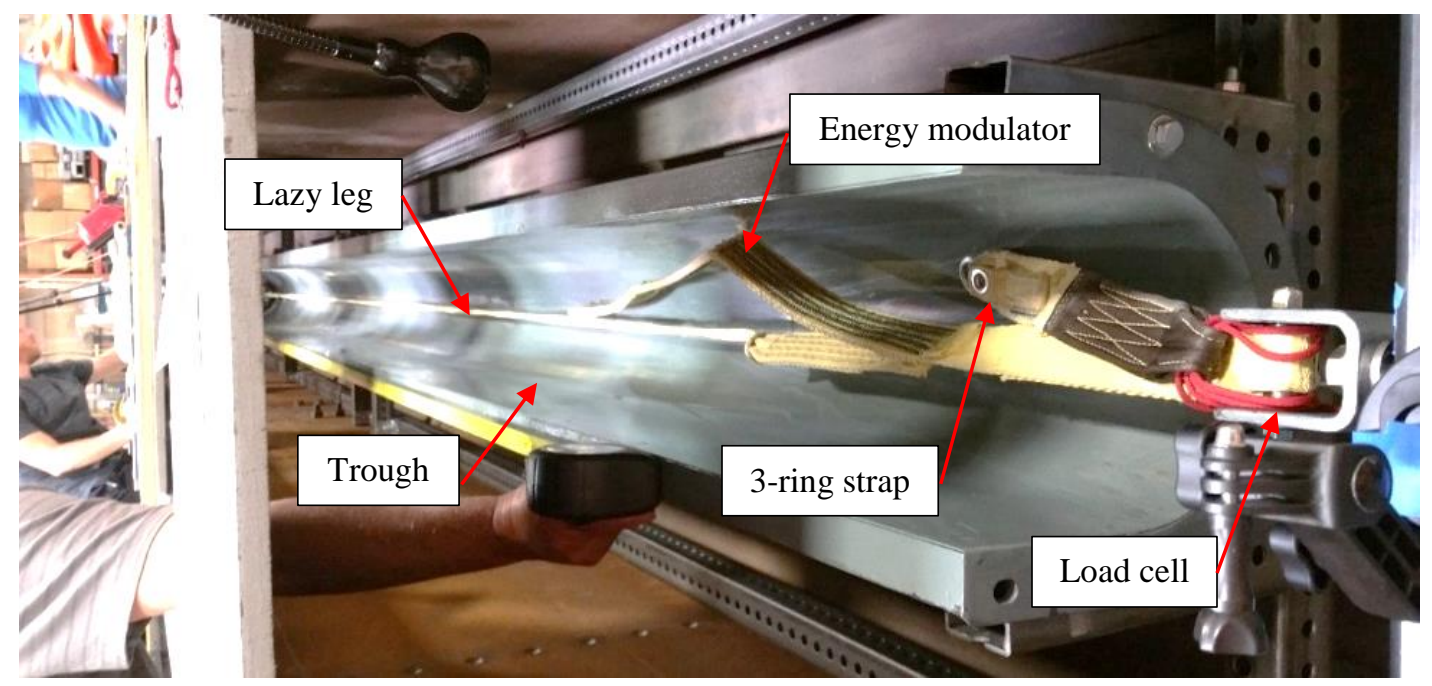

Figure 10: One End of Test Set-Up, Prior to Mass Hook-up

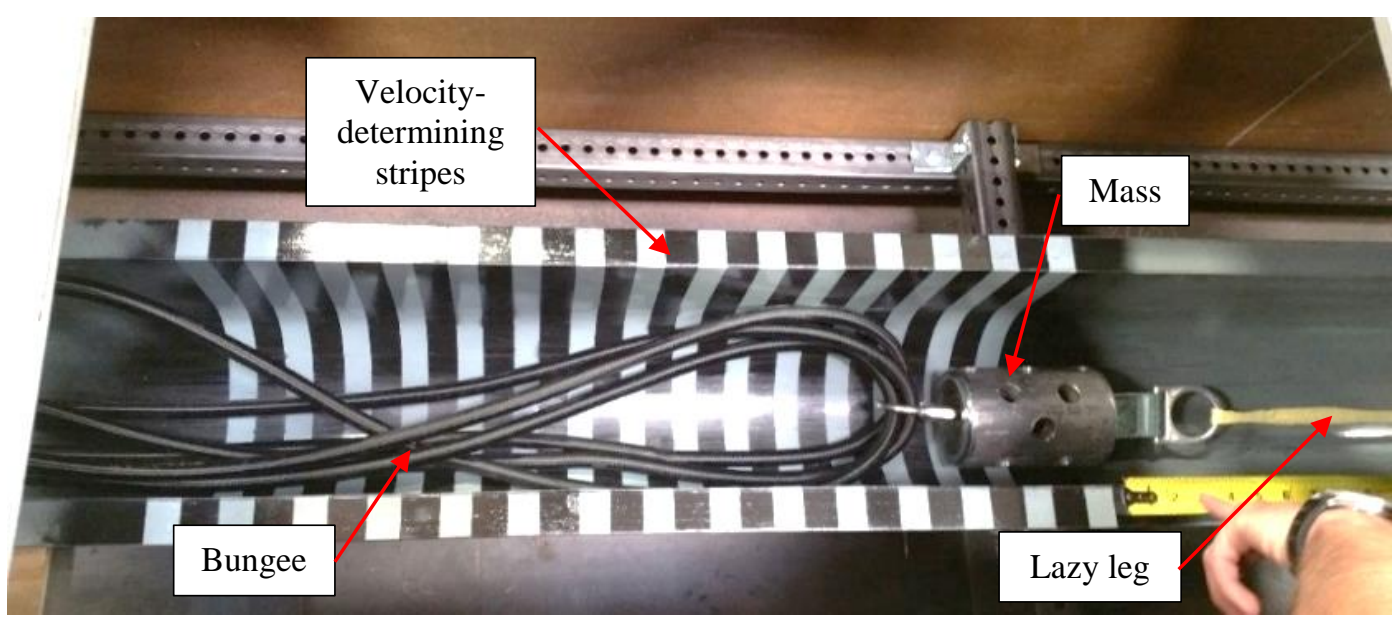

Figure 11: High Speed Camera Viewing Area, Prior to Mass Hook-Up

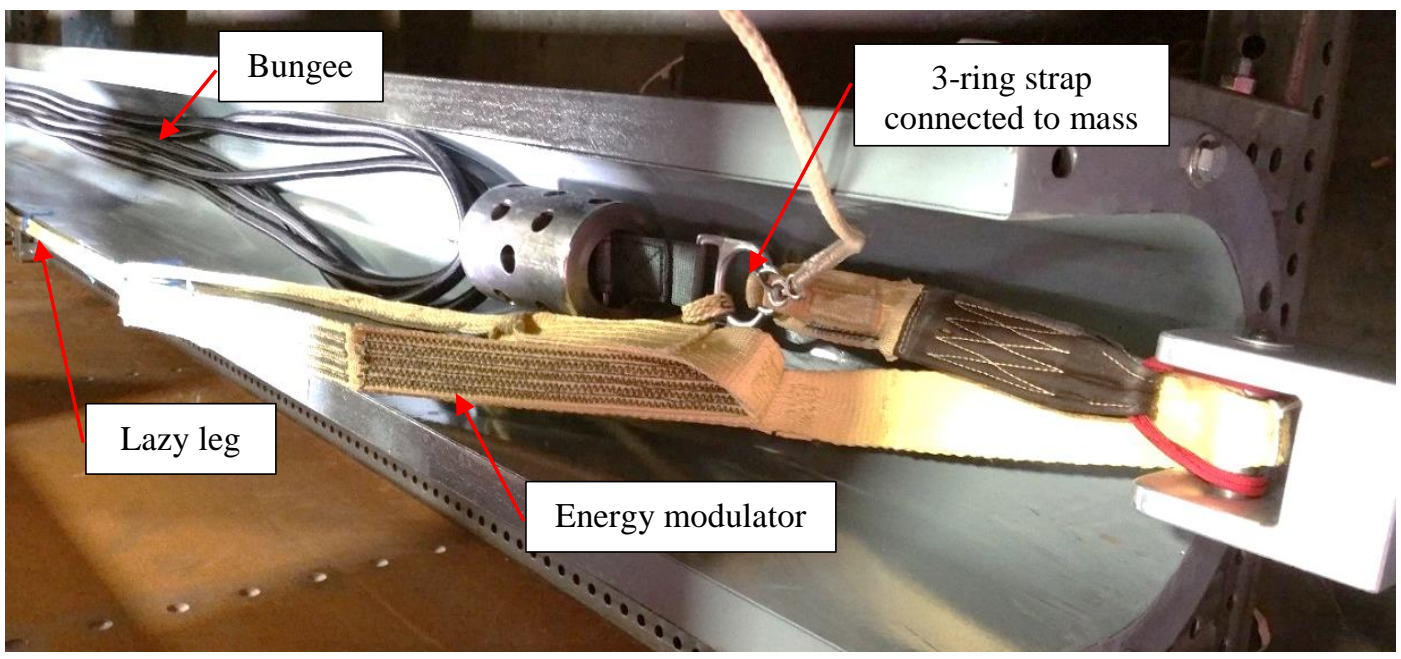

Figure 12: Mass Attached via 3-Ring, Ready to Test 


\section{B. Test Procedure}

The following gives an overview of the procedure used to perform a high-speed bungee strip-out test:

- Attach the 3-ring release to the mass (see Figure 12).

- Move the lazy leg and energy modulator out of the path of the mass (see Figure 12).

- Position the high speed camera properly in order to capture marked viewing area (see Figure 11).

- Pre-stretch the bungee to equalize loading in all of the strands.

- Ensure all personnel and unnecessary equipment are clear of test fixture.

- Stretch bungee with winch until prescribed mark is reached or until expected load for desired velocity is reached.

- Release mass via 3-ring strap.

- Replace energy modulator and reset set-up. Repeat steps for further samples.

\section{Results}

\section{Summary of Results}

The results of the tests are shown below in Table 11. Samples 1 and 2 were used for calibrating the necessary length of stretched bungee (related to the initial velocity) and are thus omitted. Samples 9 and 10 were set aside and tested using the low-speed setup (same set-up as the formal seam and joint samples). This allowed a direct comparison between the high-speed and low-speed results.

Table 11. High-Speed Bungee Test Results

\begin{tabular}{|c|c|c|c|c|c|c|c|c|}
\hline Sample & $\begin{array}{c}\text { Test } \\
\text { Type }\end{array}$ & $\begin{array}{c}\text { Load } \\
\text { before } \\
\text { Release } \\
\text { (lbf) }\end{array}$ & $\begin{array}{c}\text { Maximum } \\
\text { Tear } \\
\text { Force (lbf) }\end{array}$ & $\begin{array}{c}\text { Average } \\
\text { Tear } \\
\text { Force (lbf) }\end{array}$ & $\begin{array}{c}\text { Standard } \\
\text { Deviation } \\
\text { Tear Force } \\
\text { (lbf) }\end{array}$ & $\begin{array}{c}\text { Initial } \\
\text { Velocity } \\
\text { (ft/s) }\end{array}$ & $\begin{array}{c}\text { Initial } \\
\text { Kinetic } \\
\text { Energy (J) }\end{array}$ & $\begin{array}{c}\text { Tear } \\
\text { Length } \\
\text { (in) }^{\mathbf{a}}\end{array}$ \\
\hline 3 & $\begin{array}{c}\text { High- } \\
\text { Speed }\end{array}$ & 800 & 1539 & 1098 & 205 & 123 & 3374 & 16.25 \\
\hline 4 & $\begin{array}{c}\text { High- } \\
\text { Speed }\end{array}$ & 797 & 1427 & 1085 & 199 & 129 & 3734 & 16.25 \\
\hline 5 & $\begin{array}{c}\text { High- } \\
\text { Speed }\end{array}$ & 826 & 1517 & 1114 & 190 & 128 & 3645 & 17.25 \\
\hline 6 & $\begin{array}{c}\text { High- } \\
\text { Speed }\end{array}$ & 827 & 1508 & 1146 & 193 & 128 & 3631 & 18.75 \\
\hline 7 & $\begin{array}{c}\text { High- } \\
\text { Speed }\end{array}$ & 826 & 1517 & 1115 & 191 & 130 & 3746 & 18.50 \\
\hline 8 & $\begin{array}{c}\text { High- } \\
\text { Speed }\end{array}$ & 849 & 1580 & 1136 & 196 & 137 & 4191 & 19.25 \\
\hline 9 & $\begin{array}{c}\text { Low- } \\
\text { Speed }\end{array}$ & -- & 1442 & 929 & 209 & 4 in/min & -- & 11.75 \\
\hline 10 & $\begin{array}{c}\text { Low- } \\
\text { Speed }\end{array}$ & -- & 1392 & 971 & 159 & 4 in/min & -- & 11.75 \\
\hline
\end{tabular}

${ }^{\text {a }}$ Tear length measured along one side of energy modulator. Total tear length is twice this value.

The initial kinetic energy is one of the major factors in the tear length of the energy modulator. Figure 13 below depicts the relationship between these two parameters for Samples 3-8: 


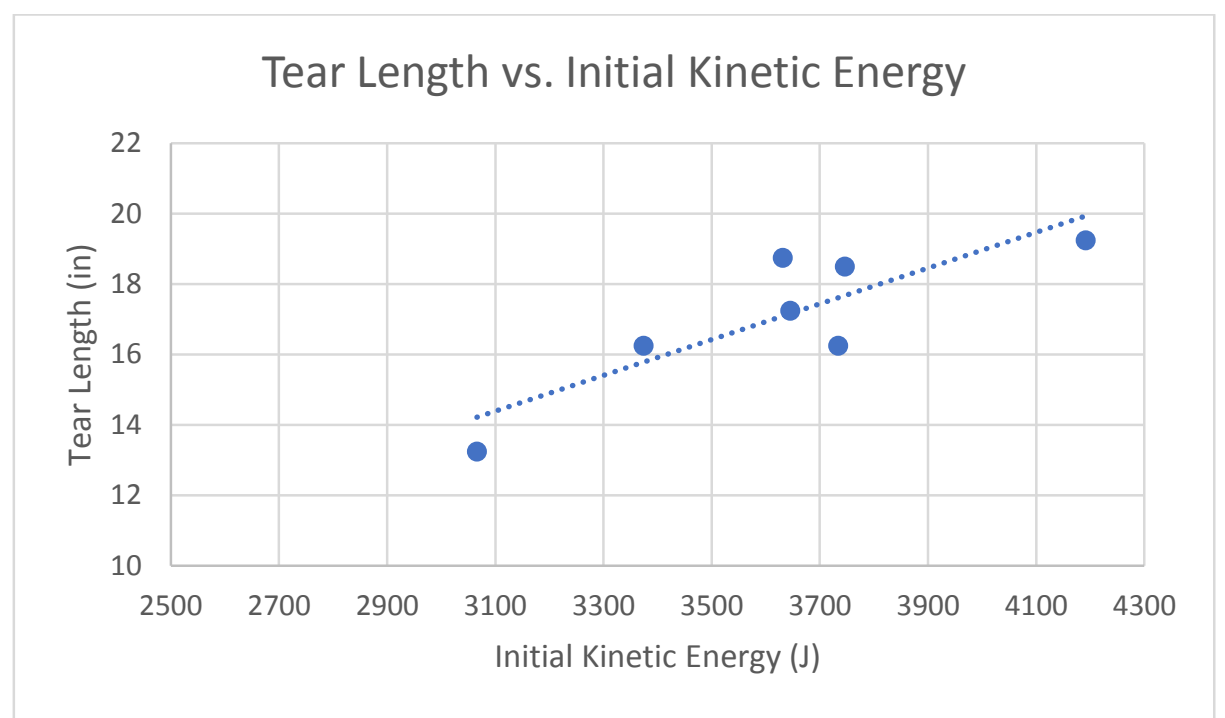

Figure 13: Tear Length vs. Initial Kinetic Energy for Samples 3-8

The goal of the testing program was to achieve velocities close to $150 \mathrm{ft} / \mathrm{s}$. Test 3 achieved an initial velocity of $123 \mathrm{ft} / \mathrm{s}$. Over Tests 4-8, the bungee was incrementally stretched further in order to increase this value to $137 \mathrm{ft} / \mathrm{s}$. While $150 \mathrm{ft} / \mathrm{s}$ was not reached, the results show that the incremental changes made between tests did not significantly affect the tear force. Figure 14 shows this progression in initial velocity over the high-speed tests:

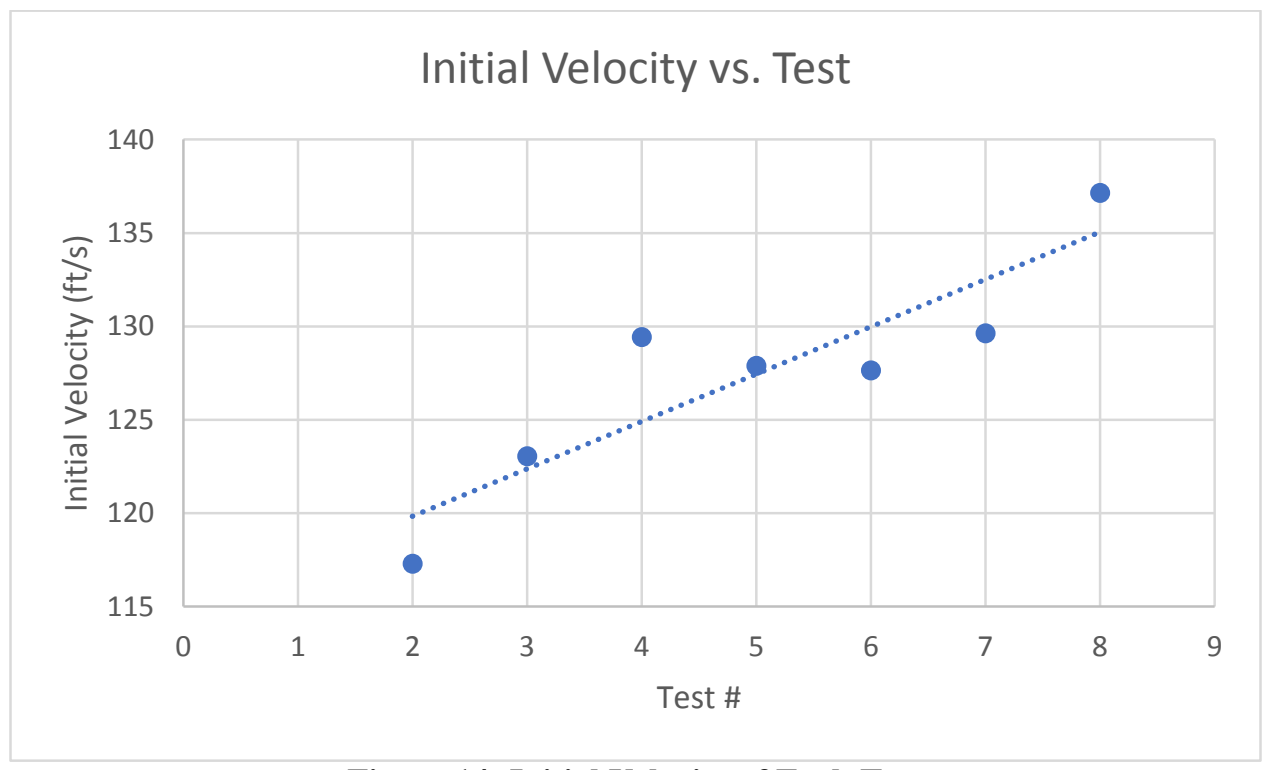

Figure 14: Initial Velocity of Each Test 


\section{Examples of Supporting Data}

The graph shown in Figure 15 below gives an example of the force measured by the load cell over time. The relevant portions of the graph are noted:

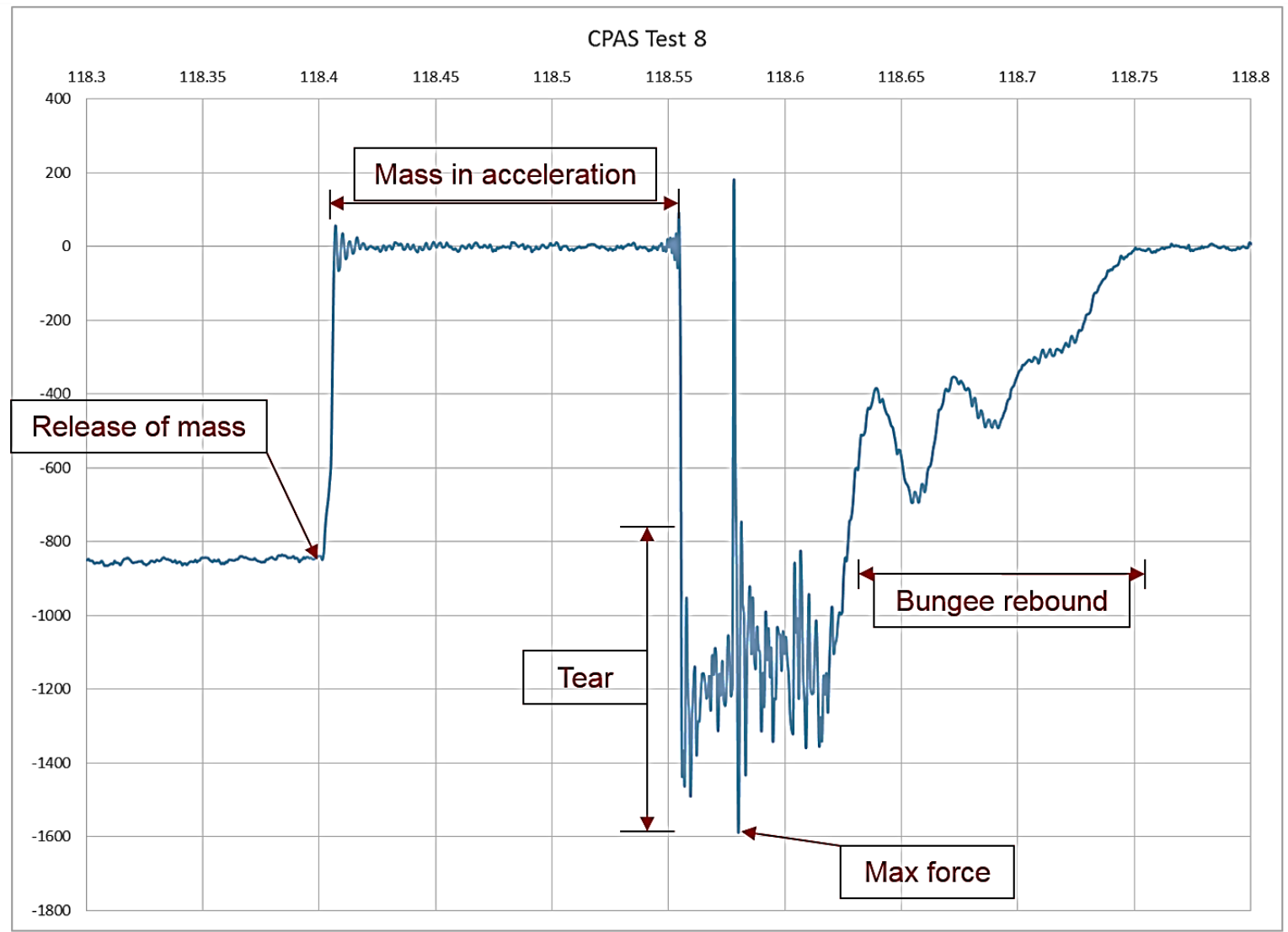

Figure 15: Load Cell Time History (Sample 8), Force (lbf) vs. Time (s)

The graph shown in Figure 16 gives an example of the mass (slug) displacement and velocity as calculated from the high-speed video: 


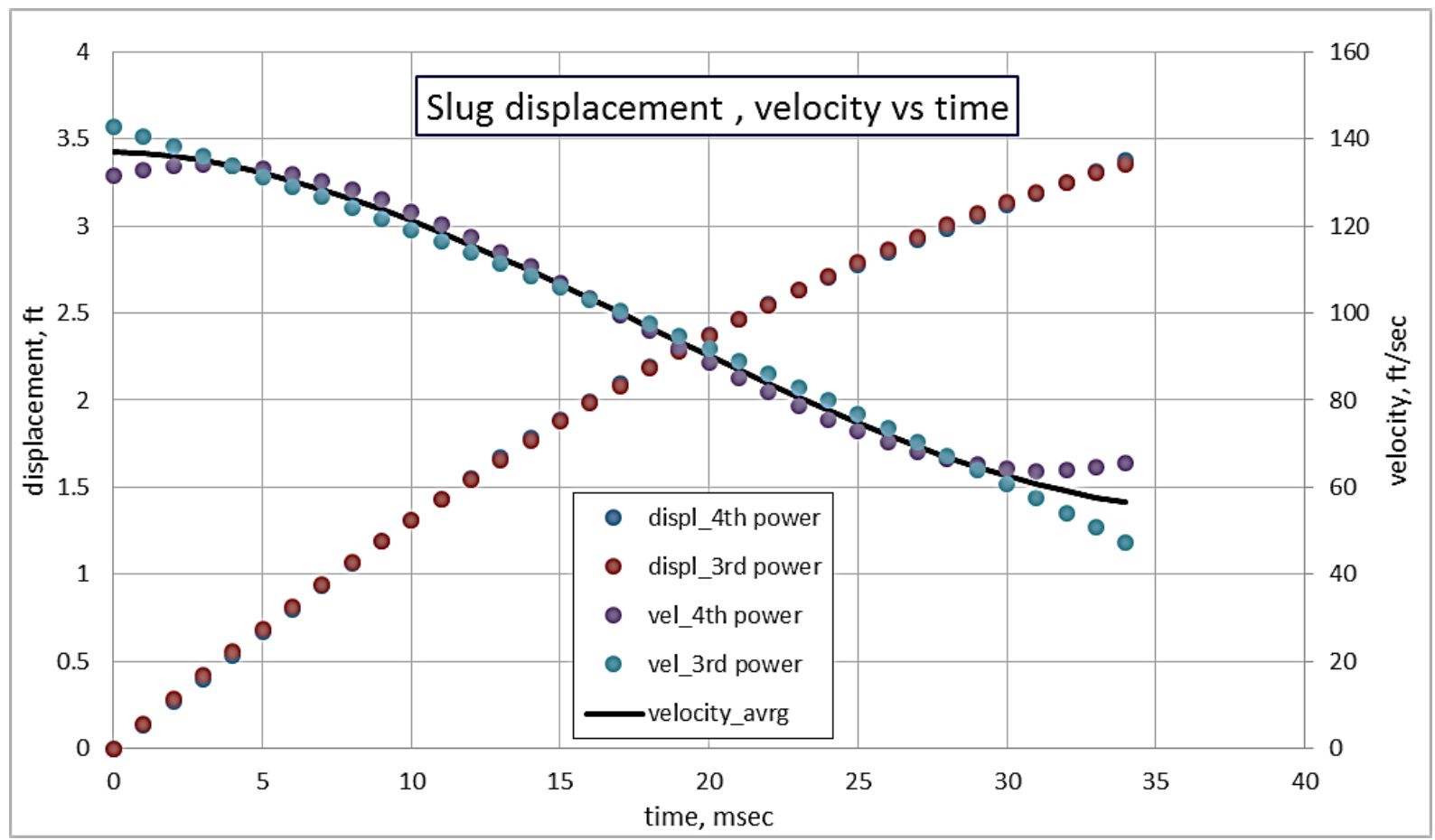

Figure 16: Slug (Mass) Displacement and Velocity over Time (Sample 8)

\section{Analysis of Results}

1. Low- vs. High-Speed Data

All test samples were constructed from the same lots of material on the same sewing machines by the same operators. Therefore, the low- and high-speed tear force results can be compared directly. See Table 12.

Table 12. Comparison of Low- and High-Speed Tests

\begin{tabular}{|c|c|c|c|}
\hline & $\begin{array}{c}\text { Low-Speed } \\
\text { (Samples 9-10) }\end{array}$ & $\begin{array}{c}\text { High-Speed } \\
\text { (Samples 3-8) }\end{array}$ & Percent Change \\
\hline Average Maximum Tear Force (lbf) & 1417 & 1515 & $+6.9 \%$ \\
\hline Average Average Tear Force (lbf) & 950 & 1116 & $+17.5 \%$ \\
\hline $\begin{array}{c}\text { Average Standard Deviation Tear } \\
\text { Force (lbf) }\end{array}$ & 184 & 196 & $+6.5 \%$ \\
\hline $\begin{array}{c}\text { Minimum Strength of Stitch } \\
\text { Pattern (lbf) }\end{array}$ & 483 & 580 & $+20.1 \%$ \\
\hline
\end{tabular}

Where the percent change is calculated by:

$$
\text { Percent Change }=\frac{(\text { High Speed })-(\text { Low Speed })}{(\text { Low Speed })}
$$

And the minimum strength of the stitch pattern is calculated by:

Minimum Stitch Pattern Strength

$$
=(\text { Average Tear Strength }- \text { St Dev Tear Strength })\left(\frac{\text { Thread Spec Strength }}{\text { Thread Actual Strength }}\right)\left(\frac{S P I_{\min }}{S P I_{\max }}\right)
$$




\section{Appearance of Low- vs. High-Speed Samples}

There was also a difference in the appearance of the samples. More Nylon thread remained in the base webbing from the low-speed tests, Samples 9-10; the remaining pieces of thread on the inside of the energy modulator were also shorter. As a comparison, there was less Nylon thread remaining in the base webbing from the high-speed tests; the remaining pieces of thread on the inside of the energy modulator were longer. This suggests that during the highspeed testing, the thread was able to slide out of the webbing more before breaking (see Figure 17).

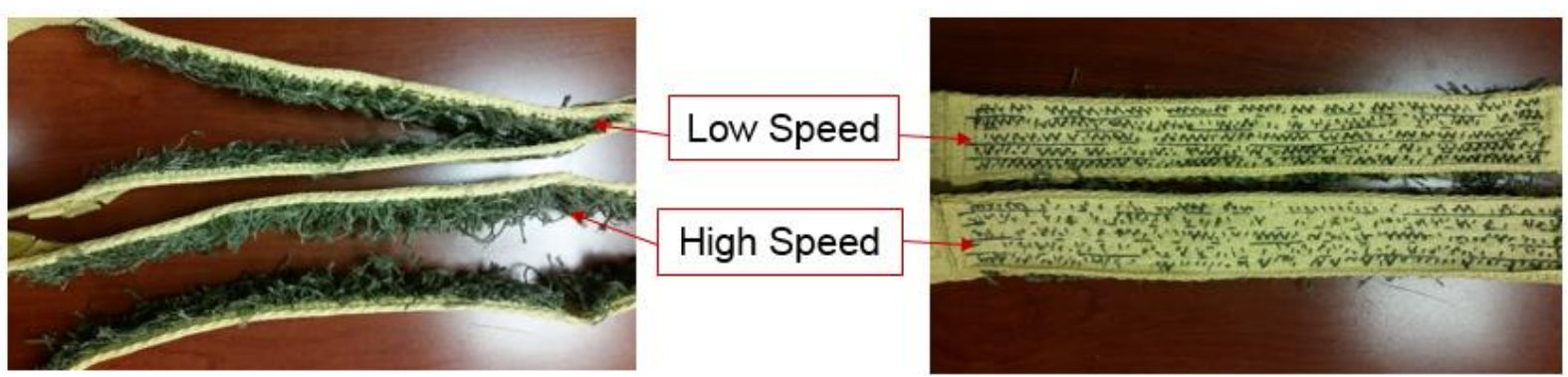

Figure 17: Low-Speed vs. High-Speed Comparison - Stitch Break Pattern

\section{Maximum Strength of the Stitch Pattern}

The purpose of the energy modulators is to prevent the load in the pilot parachute from going over the design limit load (about $7600 \mathrm{lbf}$ ). Therefore, the set of energy modulators must have a collective tear strength less than that of the pilot design limit load. The maximum stitch pattern tear strength can be calculated from:

$$
\begin{aligned}
& \text { Maximum Stitch Pattern Tear Strength } \\
& \qquad \begin{aligned}
= & \text { Number of EM })(\text { Average Tear Strength } \\
& + \text { St Dev Tear Strength })\left(\frac{\text { Maximum Thread Strength }}{\text { Average Sample Thread Strength }}\right)\left(\frac{S P I_{\text {max }}}{S P I_{\text {min }}}\right) \\
& =(4)(1116 \mathrm{lbf}+196 \mathrm{lbf})\left(\frac{87.5 \text { lbf }}{73.4 l b f}\right)\left(\frac{7}{6}\right)=7302 \mathrm{lbf}
\end{aligned}
\end{aligned}
$$

The maximum thread strength, $87.5 \mathrm{lbf}$, was determined using the same process that was detailed in Section II.0.2.

As shown from the calculation above, the maximum tear strength of all 4 energy modulators is $7302 \mathrm{lbf}$, which is less than the pilot parachute design limit load. This ensures that the energy modulators will prevent the pilot parachute from experiencing a load over its limit. 


\section{Multiple Use for Qualification Testing}

Energy modulators are typically a single use component. The energy modulator on CPAS is an integral component of the main deployment bag. Since the Orion CM (crew module) lands in the ocean, the main deployment bag (and thus the energy modulator) will be un-recoverable after a flight. But for CPAS qualification testing, there are more tests planned than there are built main deployment bags - therefore, each main deployment bag will be used multiple times. The normal post-test process for all components is to inspect and repair the assets for future use. As the energy modulator is an integral component of the main deployment bag, any stroked portion will have to be resewn. (Note that the force limiting ties should prevent the energy modulator from being stroked at lower deployment speeds.)

\section{A. Test Methodology and Procedure}

Each main deployment bag will be used a maximum of three times. Therefore, the effects on the stitch pattern strength and bridle strength were assessed through three uses. The life cycle of the samples used to determine these effects was:

- Initial stroke (1)

- Repair

- Stroke (2)

- Repair

- $\quad$ Stroke (3)

- Pull to failure

The samples used for this testing were the three samples from the initial design study that remained unbroken (Design ' $\mathrm{C}$ ').

The samples were tested on a tensile testing machine with a 30k capacity. Sedam grips were used on either end of the test fixture in order to interface with the webbing (see Figure 18).

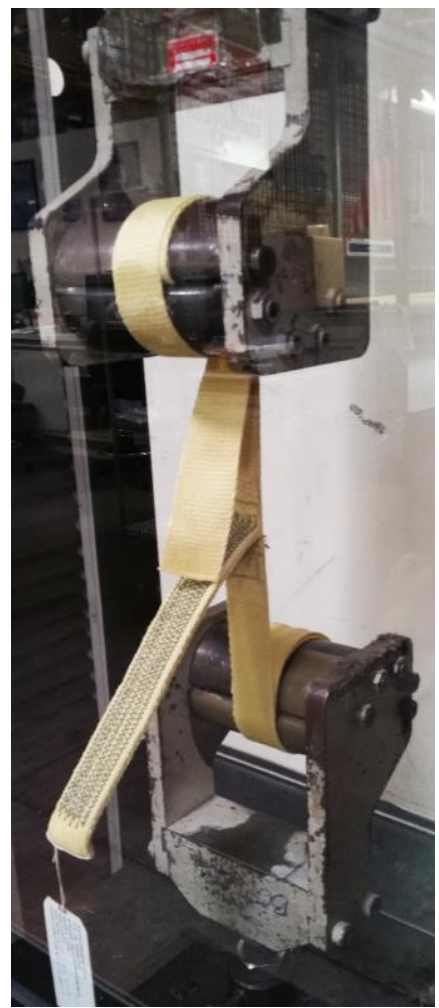

Figure 18: Formal Joint Efficiency Test Set-Up 


\section{B. Results and Analysis of Results}

1. Energy Modulator Stitch Pattern Strength

Table 13 below gives the results of the stitch pattern strength throughout three uses:

Table 13. Qual-Use Energy Modulator Stitch Pattern Strength Results

\begin{tabular}{|c|c|c|c|}
\hline & $\mathbf{1}^{\text {st }}$ Stroke & $\mathbf{2}^{\text {nd }}$ Stroke & $\mathbf{3}^{\text {rd }}$ Stroke \\
\hline Average Tear Strength (lbf) & 991 & 978 & 1076 \\
\hline Standard Deviation Tear Strength (lbf) & 106 & 154 & 173 \\
\hline Thread Specification Strength (lbf) & 54.0 & 54.0 & 54.0 \\
\hline Thread Actual Strength (lbf) & 69.4 & 69.4 & 73.4 \\
\hline Minimum SPI & 6 & 6 & 6 \\
\hline Maximum SPI & 7 & 7 & 7 \\
\hline Minimum Strength of Stitch Pattern (lbf) & 590 & 549 & 569 \\
\hline
\end{tabular}

Where the minimum strength of the stitch pattern is calculated by:

$$
\begin{aligned}
& \text { Minimum Stitch Pattern Strength } \\
& =(\text { Average Tear Strength }- \text { St Dev Tear Strength })\left(\frac{\text { Thread Spec Strength }}{\text { Thread Actual Strength }}\right)\left(\frac{S P I_{\min }}{S P I_{\max }}\right)
\end{aligned}
$$

As can be seen from comparison between the three uses (and with the results from the formal samples), there is no appreciable degradation of the stitch pattern strength throughout three uses. The slight variations in stitch pattern strength between the three uses, all within 5\% of each other, are most likely a result of the test set-up and the low number of samples, and do not indicate any actual strength differences.

\section{Joint Efficiency}

Table 14 below summarizes the results of the joint efficiency of the bridle at the energy modulator after three uses:

Table 14. Qual-Use Joint Efficiency Results

\begin{tabular}{|c|c|}
\hline Control Average (lbf) & 17,391 \\
\hline Sample Average (lbf) & 7,263 \\
\hline Sample Standard Deviation (lbf) & 191 \\
\hline Number of Plies & 1 \\
\hline Mean Efficiency & 0.42 \\
\hline Standard Efficiency & 0.41 \\
\hline
\end{tabular}

Where the efficiencies are calculated by:

$$
\begin{aligned}
\text { Mean Efficiency } & =\frac{\text { Average Breaking Strength }}{(\text { Average Control Strength })(\text { Number of Plies })} \\
\text { Standard (Joint) Efficiecny } & =\frac{\text { Average Breaking Strength }- \text { St Dev Breaking Strength }}{(\text { Average Control Strength)(Number of Plies })}
\end{aligned}
$$

The joint efficiency of the bridle after a single use, as calculated in Section III.B.1, is 0.61. After three uses, the joint efficiency has decreased to 0.41 . Although further degradation occurs to the bridle with the second and third use, the remaining bridle strength is adequate for qualification testing. This is because other degradation factors, such as temperature and contamination, are only realized during actual space flights (not test drops). 


\section{Comparison of All Tests}

During the entire design and testing campaign of the energy modulator, multiple sets of samples have been constructed and tested. While all samples were built to the same drawing, there exist a number of potential differences between the samples and tests:

- Lot (and strength) of base webbing

- Lot (and strength) of Nylon thread

- $\quad$ Stitches per inch (SPI) of samples

- $\quad$ Speed of test

- Overall construction (operator differences)

- Number of samples

Each of these variables has some effect on the results. Nevertheless, the results from all tests can be compared to some extent, as shown below in Table 15:

Table 15. Comparison of All Test Data

\begin{tabular}{|c|c|c|c|c|c|c|}
\hline Test & $\begin{array}{c}\text { Speed } \\
\text { of } \\
\text { Test }\end{array}$ & $\begin{array}{c}\text { Number } \\
\text { of } \\
\text { Samples }\end{array}$ & $\begin{array}{c}\text { Average } \\
\text { Average Tear } \\
\text { Force (lbf) }\end{array}$ & $\begin{array}{c}\text { Average Standard } \\
\text { Deviation Tear } \\
\text { Force (lbf) }\end{array}$ & $\begin{array}{c}\text { Actual } \\
\text { Thread } \\
\text { Strength (lbf) }\end{array}$ & $\begin{array}{c}\text { Minimum } \\
\text { Stitch Pattern } \\
\text { Strength (lbf) }\end{array}$ \\
\hline $\begin{array}{c}\text { Initial Design } \\
\text { Study }\end{array}$ & Low & 6 & 991 & 106 & 69.4 & 590 \\
\hline $\begin{array}{c}\text { Qual Re-Use after } \\
\mathbf{2}^{\text {nd }} \text { Stroke }\end{array}$ & Low & 3 & 978 & 154 & 69.4 & 549 \\
\hline $\begin{array}{c}\text { Qual Re-Use after } \\
\text { 3 }^{\text {rd }} \text { Stroke }\end{array}$ & Low & 3 & 1076 & 173 & 73.4 & 569 \\
\hline $\begin{array}{c}\text { Formal Joint } \\
\text { Efficiency Samples }\end{array}$ & Low & 10 & 962 & 153 & 69.4 & 540 \\
\hline $\begin{array}{c}\text { High-Speed Study } \\
\text { Samples 9-10 }\end{array}$ & Low & 2 & 950 & 184 & 73.4 & 483 \\
\hline $\begin{array}{c}\text { High-Speed Study } \\
\text { Samples 3-8 }\end{array}$ & High & 6 & 1116 & 196 & 73.4 & 580 \\
\hline
\end{tabular}

Where the minimum strength of the stitch pattern is calculated by:

$$
\begin{aligned}
& \text { Minimum Stitch Pattern Strength } \\
& \qquad=(\text { Average Tear Strength }- \text { St Dev Tear Strength })\left(\frac{\text { Thread Spec Strength }}{\text { Thread Actual Strength }}\right)\left(\frac{S P I_{\min }}{S P I_{\max }}\right)
\end{aligned}
$$

Where the thread specification strength was $54 \mathrm{lbf}$ and the SPImin/SPImax was 6/7.

It can be seen that throughout the different tests, the minimum strength of the stitch pattern was consistent. 5 of 6 tests had values between 540 and $600 \mathrm{lbf}$. The one test with a minimum tear strength below $500 \mathrm{lbf}$, the two low-speed samples from the bungee testing, consisted of only two samples; this resulted in a high standard deviation which drove the minimum tear strength lower.

While the high-speed samples from the bungee testing had a higher tear strength than the low-speed samples from the same lot, the minimum tear strength of these samples was in family with all of the other low-speed samples. It can therefore be said that there are only small differences in tear strength between the low- and high-speed tests. 


\section{Conclusion}

In order to mitigate potentially high pilot snatch loads, an energy modulator was incorporated between the bag handles of the main deployment bag and the pilot retention release bridle. This energy modulator was initially designed using the results from a small number of samples during an initial design study. In order to formalize and validate these results, two additional sets of samples were constructed. The first set was tested using CPAS standard slowspeed seam and joint testing methods in order to determine the degradation to the base bridle webbing. The second set of samples was tested under high-speed conditions to ensure that the design was still adequate under conservative flight-like conditions. A subset of the initial design samples was also repeatedly tested throughout multiple uses to simulate repair and reuse throughout qualification testing.

The energy modulator was designed to have a high tear force with minimal degradation to the base webbing. This tear force was ensured to be lower than the pilot design limit load under maximum conditions (the strongest thread with the highest SPI, e.g.). Additionally, a set of force limiting ties was incorporated to keep the energy modulators from stroking under low loads. The final design, extensively tested in low- and high-speed conditions, consists of 5 rows of zigzag stitch interspersed with 4 rows of straight stitch, all comprised of Nylon thread. This design was seen to have comparable performance under high- than low-speed conditions.

\section{Acknowledgments}

Many thanks to Vladimir Drozd, Kristina Peterson, Robert Sinclair, Kyle Starr, and Matthew Zwicker, who designed and ran the high-speed bungee tests, and who also analyzed some of the data. And thanks to Airborne Systems manufacturing, for agreeing to sew multiple rows of ' 6 ' cord zigzag on such long stretches of thick webbing.

\section{References}

${ }^{1}$ Mollmann, Catherine, "Determination of Parachute Joint Factors using Seam and Joint Testing," AIAA 2015$2125,2015$. 